\title{
EFFECTIVE CARTOGRAPHIC METHODS FOR ASSISTING TACTICS CHOICE AND INDOOR DEPLOYMENTS DURING BUILDING FIRES - A CASESTUDY THE DUTCH FIRE BRIGADE
}

\author{
T.W.T. van der Meer ${ }^{1}$, E. Verbree ${ }^{2 *}$, P.J.M. van Oosterom ${ }^{2}$ \\ ${ }^{1}$ MSc Geographical Information Management \& Applications (GIMA) \\ t.w.t.vandermeer@students.uu.nl \\ ${ }^{2}$ GIS Technology, OTB Research Institute for the Built Environment, Delft University of Technology, the Netherlands \\ (e.verbree, p.j.m.vanoosterom)@tudelft.nl
}

Commission IV, WG IV/5

KEY WORDS: Indoor Cartography, Indoor Geovisualization, Fire Brigade, Mobile GIS, ToggleMaps, Emergency Services

\begin{abstract}
:
Information is key for a safe deployment of the fire brigade. Incorrect judgement could lead to decreased effectivity or even casualties. Because of the risks that are posed by building complexity and modern building materials, the Dutch fire brigade is increasingly hesitant to enter the building during a building fire. While no two building fires are the same and personal judgement of the fire brigade will remain necessary, good information supply could aid the commanders in making the right choices. There are a lot of factors that come into play when choosing strategy, tactics and techniques. An effective information system should present the right and up to date information at the right moment, and it should do so in an intuitive and effective manner. Most cartography research has been done for outdoor applications; indoor cartography is in its infancy. This research aims to develop cartographic methods to aid the Dutch fire brigade during building fire deployments. Based on the requirements of the organization a novel approach is introduced: ToggleMaps. This mobile interface combines a main map pane with a reference pane, both in either $2 \mathrm{D}$ or 3D and with either a low or a high level of detail. This allows the user to toggle between two states: a detailed 2D overview of a separate building level with its perspective within the 3D reference map, or a more detailed 3D overview of the whole building with a simplified 2D reference map of his current building level.
\end{abstract}

\section{INTRODUCTION}

On 9 May 2008 there was a fire in a shipyard in De Punt, a village in the Dutch province Drenthe. Upon arrival the firefighters saw thick smoke with an unusual yellow colour. During an indoor exploration of the building these yellow fumes ignited resulting in a large explosion and the death of three firefighters. This tragic accident led to the realisation of the Dutch fire brigade that they did not know enough about fires in buildings with modern building materials, and that the former guidelines for indoor deployments were not safe enough for large complex buildings. This realisation led to the development of the 'Brandweerdoctrine' (Fire brigade doctrine), a combination of previous findings and new strategies and methodologies for firefighting. The first product of the Brandweerdoctrine is the report on the quadrant model for fighting building fires (Hagen, Hendriks \& Molenaar, 2014). This report is a framework for tactics choice, and it explains which incident factors affect the choice of tactics. For each tactic a different subset of techniques exists. This makes the total number of incident factors very large, how can this be presented in a way that is helpful during a deployment? ${ }^{1}$

Information is key for a safe deployment of the fire brigade. Incorrect judgement could lead to decreased effectivity or even casualties. Because of the risks that are posed by building complexity and modern building materials, the Dutch fire brigade is increasingly hesitant to enter the building during a fire (Hagen, Hendriks \& Molenaar, 2014). While no two building fires are the same and personal judgement of the fire brigade will remain necessary, good information supply could aid the commanders in making the right choices. There are a lot

\section{* Corresponding author}

of factors that come into play when choosing strategy, tactics and techniques. An effective information system should present the right information at the right moment, and it should do so in an intuitive and effective manner. Most cartography research has been done for outdoor applications; indoor cartography is still in its infancy (Lorenz et al., 2013). Previous research has shown a number of possibilities depending on the purpose of the map, the medium used and the expert level of the user. Solutions were often either focussed on routing (Lorenz et al, 2013) (Puikkonen et al., 2009) or on the location of features within the building (Nossum, 2011). What if the user wants to do both? Another challenge is giving an overview of all building levels within a single view. Current efforts often let the user switch between building levels (Nagi, 2014) (Toutziaris, 2017). This gives the user detailed information about his current building level, but the perspective within the building as a whole is lost. Lorenz et al (2013) proposed a single oblique 3D view of only corridors which proved effective for navigation, but when rooms need to be displayed there might be occlusion issues. Nossum (2011) proposed an innovative method (IndoorTubes) for combining all building levels in a single view with differently coloured lines representing corridors on different building levels. However users claimed to preferred separate building floor maps in a user study (Nossum \& Nguyen, 2012).

This research aims to develop cartographic methods for presenting indoor building information to help the Dutch fire brigade (section 2) in tactics choice and choice of indoor methods and navigation. Indoor maps have most added value for complex buildings, so the research will focus on these. The requirements from the Dutch fire brigade were assessed with the help of interviews and literature studies (section 3). Finally these findings were combined (section 4) to introduce a novel 
method for indoor cartography: the ToggleMap. Finally, we draw some conclusions in section 5 .

\section{BACKGROUNDS OF THE DUTCH FIRE BRIGADE}

The Dutch fire brigade has many tasks ranging from animal rescue to cleaning dangerous substances. The goal of this research is to develop cartographic methods that assist them during indoor building fire deployments. The Dutch fire brigade is a complex organization with many ranks, organizational layers and positions. There are specialized units such as diving teams or technical rescue teams each with their own specialized materiel. A standard unit consists of a crew of 5 firefighters and a commander manning a single water tender (van Alphen \& Jongerden, 2013):

- Driver / water pump operator: responsible for transporting the unit and the equipment to the incident and operating the water pump.

- An attack team of 2 persons: responsible for exploration of the incident, fighting fires or rescuing persons.

- $\quad$ Water unit of 2 persons: responsible for water supply from either a water tank on the vehicle, fire hydrants or water bodies.

- Commander: responsible for the safety of his / her crew, communication and delegation of tasks. The commander can support the attack team too.

Complex building fires require at least two water tenders. The commanders of these units are led by an officer in charge, or a head officer in charge in case of very large incidents. These officers coordinate the deployment by delegating tasks between different units.

The following characteristics of a building are used to decide upon its deployment complexity, although this identification is incident-dependent (Veiligheidsregio Rotterdam-Rijnmond, 2010):

Building properties require an automatic fire alarm.

- $\quad$ Dry or wet pipes or risers are present

- $\quad$ Penetration depth (distance between the water tender and the fire or smoke compartment) is more than 60 meters

- $\quad$ Large fire compartments (> $1000 \mathrm{~m} 2$ surface area)

- Cluttered / unclear interior with for example differences between building layers or a lack of landmarks

- $\quad$ Orientation / exploration of indoor spaces by walking alongside a wall is impossible

Actions during a deployment can be divided in six phases (Figure 1) from the first alert to packing up after a completed deployment. During the alert phase some basic information is provided: the address and the name of the building, the type of incidents and which units are needed. During the en route phase the commander collects information (hence: the attack plan) about the incident from the communication room (van der Meer, 2016). The time between the first alert and on-site arrival is short: Dutch norms for arrival times range from 5 to 10 minutes depending on the building type (Brandweer, 2018).

The Renewed View on Firefighting urges firefighters to step back and plan the deployment. Fires in closed building structures (no air flow towards the fire source) do not spread rapidly and in many cases the fire brigade has more time to reflect than they think. Taking time to collect information and plan a deployment instead of using routine solutions is more effective, even when rescue is needed (Brandweeracademie, 2018). An important tool for assessing the degree is the scheme of characteristics (Hagen, Hendriks \& Molenaar, 2014). It discusses human characteristics, building characteristics and fire characteristics. Human characteristics describe the selfreliance and perceptivity of the people in the building. It is also about organizational factors: is there a well-functioning emergency response team? Building characteristics affect the development of building fires and the safety of fire brigade deployments. With fires in complex buildings there is a list of things that the fire brigade should know in order to perform a safe deployment (Brandweer Rotterdam-Rijnmond, 2017):

- $\quad$ Fire behaviour of building construction and materials

- $\quad$ Fire preventive measures

- $\quad$ Fire repressive resources in the building

- $\quad$ Building use types

- $\quad$ Building height

- $\quad$ Number of building levels

- $\quad$ Building layout

- $\quad$ Location of water riser pipes

- $\quad$ Number of hose lengths between the water riser pipes and the fire

Accessibility of rooms

- Number of staircases

- Number of staircases and their location

- $\quad$ Number of firefighter's elevators and their location

- $\quad$ Location and capacity of fire hydrants

- $\quad$ Number of hose lengths between fire hydrant and vehicle

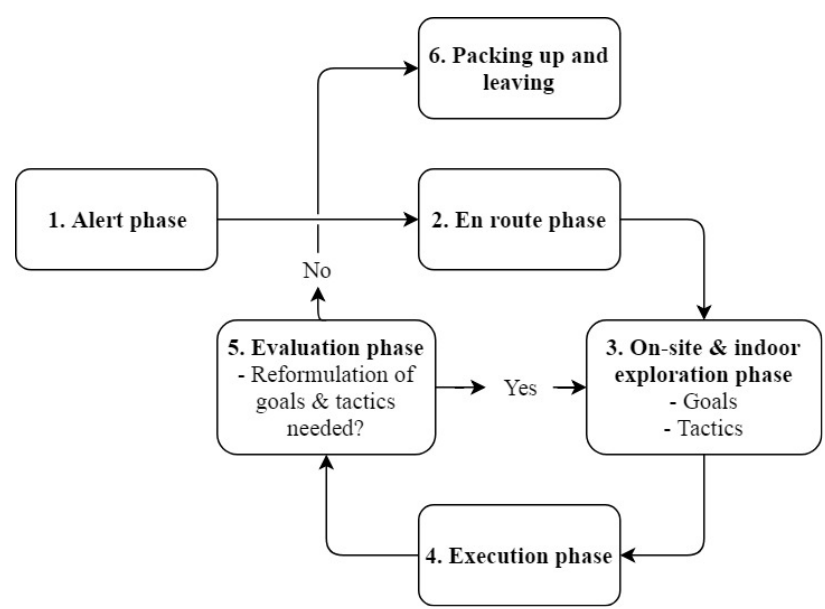

Figure 1: Phases of a complex building fire deployment

Fire characteristics explain the nature of the building fire. These building fires can be fuel controlled or ventilation controlled. If the size of the fire depends solely on the amount of fuel being burned, then the fire is fuel controlled. Many building fires start as fuel controlled fires. Once the fire grows and more fuel is ignited, more oxygen is needed to sustain the fire. Oxygen can become a limiting factor if the room is closed and the fire becomes ventilation controlled.

The fire brigade does not only look at the current state of the fire, but also at the potential development of the fire. The biggest danger during a deployment is a sudden supply of oxygen to a ventilation controlled fire, as this can cause rapid expansion of the fire or combustion of smoke gasses (Brandweeracademie, 2016). The SAHF model (RSTV model in Dutch: Rook, Stroming, Temperatuur, Vlammen) is an important tool for this. It encompasses four indicators for fire 
potential: Smoke, Air-Track, Heat and Fire. It can be applied to building fires as a whole, or for separate fire compartments. The RSTV model distinguishes between six different states (Brandweeracademie, 2018):

1. Clean: none of the SAHF indicators are present

2. Fuel: thick smoke is an indicator for presence of flammable fire gases

3. Air-Track: when air visibly flows towards a fire source and/or it is able to mix with smoke or fuel within a compartment we're speaking of air-track

4. Heat: when smoke has a high temperature and / or an ignition source is present, we're speaking of heat

5. Fire hazard: when fuel, air-track and heat are all present, there is a high risk of combustion.

6. Fire: when flames are visible, the SAHF triangle is complete and we are speaking of a fire

With the incident characteristics the fire brigade can now choose operational tactics within the so-called quadrant model with two dimensions: indoor/outdoor - defensive/offensive (Figure 2). This is a consideration between the risks and reward. If rescue of people is possible, the fire brigade is willing to take extra risks and the Dutch occupational health regulations are more flexible when this is possible (Davits, van Beek \& Koomans, 2013).

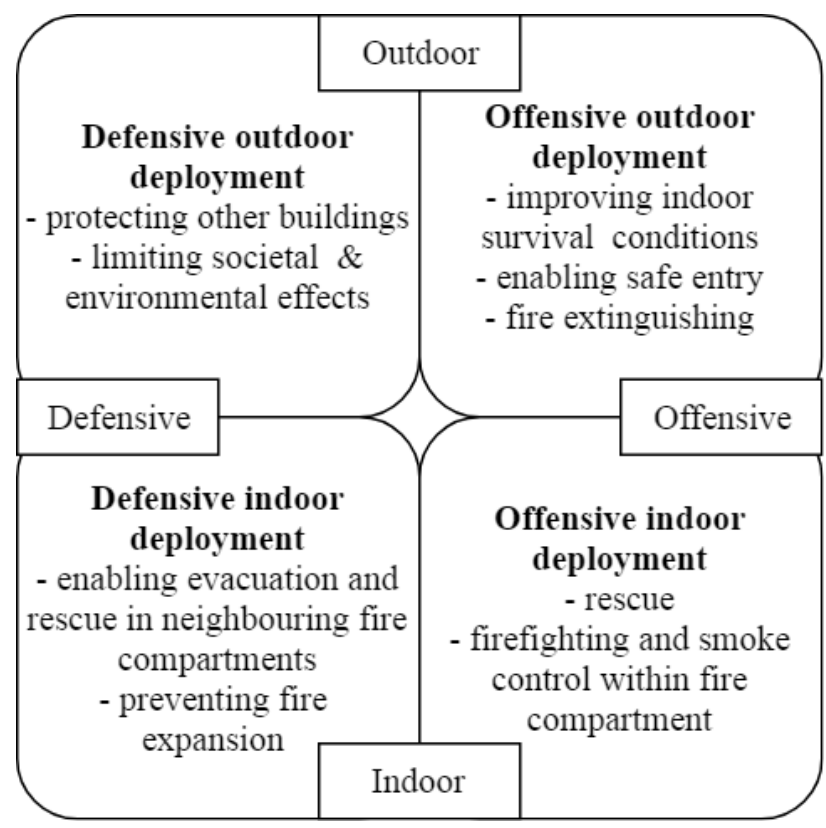

Figure 2: The quadrant model

(Hagen, Hendriks \& Molenaar, 2014)

Given that circumstances allow an indoor deployment in the first place, the fire brigade starts with an indoor exploration moving towards the fire source. Previously they have consulted digital or paper maps of the building, but these are not always present. As an officer in charge on this topic stated:

"Relying on assumptions is dangerous. Often firefighters will assume that buildings of the same type also have the same interior, or that building levels are identical to each other. In reality this can be different so it is important to verify our assumptions during a deployment"

During the indoor exploration the attack team tries to find the fire source, determine attack routes and verify whether the fire can be extinguished with already present hose reels. Using these hose reels is not official practice, but it allows the attack team to respond quickly before the fire expands (Brandweer Rotterdam-Rijnmond, 2017). Should these hose reels be insufficient, the commander will choose a deployment plan and choose tactics. He will also choose a location for a beachhead, a safe location from where the deployment can be coordinated. Materiel is also stored at this beachhead. In the meantime the water unit and the pump operator take care of water supply for the attack team. The second water tender takes over the tasks of the water unit once they arrive, so they can assist the deployment from the beachhead. Tasks of extra units depend on the incident. If a fire control panel is present, one firefighter will check whether fire and smoke is expanding to other rooms during the deployment. The situation could call for additional attack teams to assist the first attack team on the same location, or they could be deployed on other locations in the building as well. Another common task for the second water tender is to supply the beachhead with extra materiel. These tasks are delegated by the officer in charge. (Brandweer Cluster Amerstreek, 2010), (Veiligheidsregio Rotterdam-Rijnmond, 2010).

The attack teams either target the fire source directly or they visit the surrounding rooms one by one depending on the tactics of the deployment. They carefully consult indicators from the SAHB model to respond accordingly. They have specific fire hose nozzle techniques for cooling smoke gases, extinguishing fire or shielding themselves from heat (Spithorst, 2015).

\section{SYSTEM REQUIREMENTS}

Defining system requirements in this context is a challenging task. During interviews it became clear that visions and requirements about information systems not only vary vertically among different positions within the fire brigade, but also horizontally among different persons. The outcomes in 'The Renewed View on Firefighting’ (Brandweeracademie, 2018) prove that a more information-driven approach is safer and more effective when fighting building fires. System requirements for the indoor cartography development of this research are based on these outcomes. This means that the results will not appeal to all end users but an attempt will be made to consider their needs as best as possible. One officer in charge and knowledge director from the fire brigade stated:

"Effectivity is quality multiplied by acceptance. We must not only invest in the quality of the innovation itself, but also in the acceptance by the end user. It is important to thoroughly explain the functionality of the innovation and how this can help the user. This process is called the soft side of innovation and requires a lot of experience with firefighters."

Several interviewees stated that their current information systems often supply too much information at once, but they also agree that all features in the system are useful in some part of the process. Dosage of information in the right form, at the right time and to the right person is important. Assuming that the Renewed View on Firefighting (Brandweeracademie, 2018) will be the national norm in firefighting in the future, an indoor information system could be a good addition to deployments. It could help firefighters adopt a data-driven approach to create customized deployment plans for each incident. Moreover firefighters stated that it would be useful to keep track of fire expansion and personnel. The aim of the indoor visualizations will therefore be twofold: 
- $\quad$ Assisting during on-site and indoor exploration to help formulate an effective deployment plan

- $\quad$ Tracking fire expansion and personnel during a deployment and show this in (near) real-time on the (to be designed) indoor map.

Information needs vary between different functions. A commander explained:

"The attack team needs information for operational tasks, such as the location of a fire and fire hose connectors in the building. Commanders are operating on a higher abstraction level to delegate tasks among crew members. An officer in charge looks at the building as a whole and is also interested in environment characteristics. He wants to know which crew is doing what, and is less interested in detailed information for practical tasks"

The water unit and pump operator are mainly occupied with finding water sources, ensuring water supply and connecting to the right water riser pipes. Information for this is sufficiently supplied in the current paper and digital attack maps, so these crew members have less need for an additional information system. Interviewees stated that the attack team is too heavily packed and too much concerned with safely executing commands from the commander to consult a mobile information system. A lector on firefighting science proposed the following:

"It is important to be flexible when it comes to deployment procedures, and not to be afraid to change these if that causes more effectivity and safety. It would for example be possible to deploy a third person with the attack team as a navigator"

In some cases a third person already accompanies the attack team with a thermal imager. Another person mans the fire alarm control panel to warn others in case of fire expansion. If this control panel were linked to the system, all users would have direct access to this information. The firefighter previously manning the fire alarm control panel could then assist the attack team as a navigator. The officer in charge and head officer in charge manage teams in different areas both inside and outside the building. They are mainly interested in tracking the teams and communicating about their position, but also the addition of tactical information such as hidden building shafts that could disperse smoke. These requirements show the importance of indoor maps showing (near) real-time information. General requirements of all user groups are about durability and wearability without impeding their tasks. Given the fact that many incident factors affect deployment choices, firefighters also stated that they are not looking for systems that provide standard solutions. A commander stated on this topic:

"Doctrines are mainly useful for standard deployments. Divergent deployments require personal judgement of the situation. The system should provide information and provoke thinking instead of supplying specific procedures."

When given the choice between $2 \mathrm{D}$ or $3 \mathrm{D}$ representations, interviewees often stated that both would be of added value. 2D floor maps are needed for both the overview as the detailed information, but they do not show the shape of the building or what is present on other building levels.

Finally there is the choice of display device. There are two main solutions that would keep the hands of the firefighters free: an Augmented Reality display in the Self-Contained Breathing Apparatus (SCBA) or a wrist-mounted smartphone. The AR display appealed to the imagination of both commanders and officers in charge; they envisioned a system that projected routes and building features on top of the real world. However this would require indoor positioning techniques that not only record a person's exact position, but also his viewing direction. Because this is expensive and complicated to achieve in a large number of complex buildings (Brassil, 2014), the choice was initially made to further focus on wrist-mounted smartphones.

\section{TOGGLEMAPS}

Given the fact that indoor cartography is in its infancy and the fire brigade has relatively complex system requirements, it is important to think outside the box. A novel approach for indoor cartography is proposed called the ToggleMap (Figure 3). ToggleMap is an interface with two map panes with linked views.

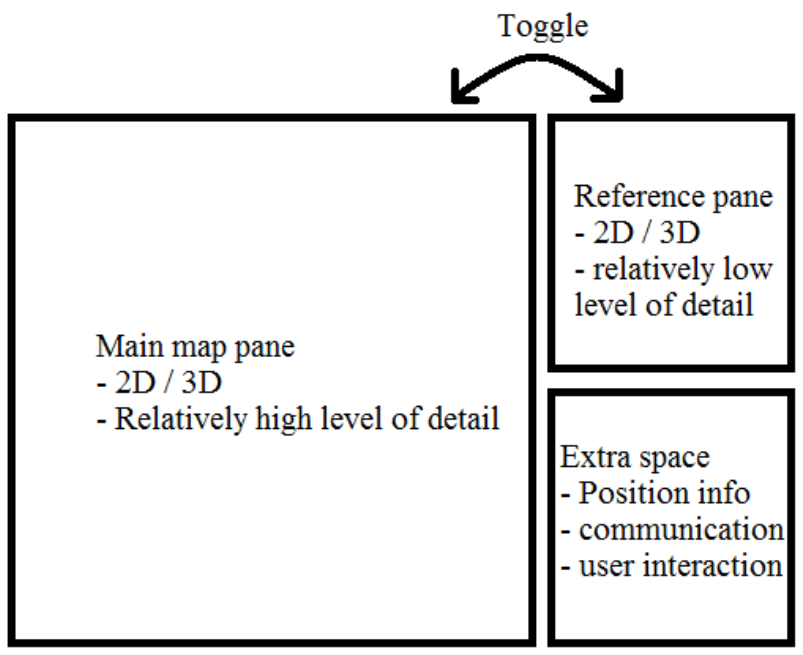

Figure 3: Proposed layout for ToggleMaps

This interface proposes different map states: a 2D top-down view of a single floor or a 3D oblique view of all corridors and rooms on a single floor, both with either a (relatively) high or a low level of detail. The interface has a main mapping pane showing the 2D or 3D map with a higher level of detail and a reference map pane with the other representation in lower detail. The user can toggle between 2D and 3D in these two map panes. ToggleMaps allow the user to view detailed information about a single floor in 2D and basic routing information in $3 \mathrm{D}$ in a single view, and he can toggle to view a more detailed 3D model with a basic 2D model that shows only corridors, exits and staircases. The fire brigade wants to access their information with as little user interaction as possible. Physical buttons are needed to make the system operable during building fire deployments. At least two inputs are needed:

- $\quad$ A button to toggle between 2D and 3D views

- $\quad$ A button to rotate the views in order to be able to see occluded areas in 3D. Horizontal viewing angles should be linked between the two map panes so the user can mentally connect the two

A button for panning / zoom in or out

Linked map views have been applied in outdoor applications before to allow users to visually inspect relations between separate map layers (Roberts, 2005). The novelty of ToggleMaps is within the indoor application, the ability to 
toggle between dimensionality and the difference in hierarchy: the main mapping pane is used for the finding the information that the user needs, and the reference pane is meant for bringing that information in perspective for orientation. This perspective is either within the building as a whole in $3 \mathrm{D}$ view or within a single building level.

\section{CONCLUSIONS}

In this research a new method for indoor cartography was proposed, meant for mobile devices. An assessment of fire brigade methods and user requirements was made. The challenge was to create methods to display detailed building data on a small display while giving the user their perspective within the building as a whole.

The current design is still conceptual. Further work needs to be done in order to create a working ToggleMap prototype. It is inevitable that during this process problems will occur. Concessions need to be made about what to display and what not to display, the screen size of a smartphone will be a restrictive factor.

With this prototype user tests can be conducted to iteratively improve the design. Resistance from users is also expected because technical innovations can be a sensitive subject for users in dangerous environments. The added value of indoor information systems needs to be explained thoroughly in order to promote acceptance.

Further work could also be devoted to the application of ToggleMaps in other fields such as shopping mall navigation systems or mobile maps for large hospitals. An interesting research question would be whether the combination of $2 \mathrm{D}$ and $3 \mathrm{D}$ and the option to toggle helps the user with orientation.

Currently we are in the process of refining ToggleMaps and visualizations and symbol development within the map panes. This process will be conducted with input from firefighters.

\section{ACKNOWLEDGEMENTS}

We thank the following people for their contributions to this research:

Fire department research supervisors:

- Vincent Oskam, Data Scientist Fire Brigade Intelligence, VRR

- $\quad$ Huib Fransen, head officer in charge, VRR

And our interviewees:

- $\quad$ Rogier Piek, officer in charge, VRR

- $\quad$ Maurice de Beer, knowledge director and commander in charge

- $\quad$ Ricardo Weewer, lector in firefighting science, IFV

- Morgan Bremer, operational information officer, VRR

- $\quad$ Susila Haspels, preparation specialist, Schiphol

- Jeffrey Tolboom, preparation advisor, Schiphol

- $\quad$ Ben de Wilt, commander, VRR

- $\quad$ Gert Wesdijk, commander, VRR

- Marcel Henderson, head of operational information, VRR

- Dennis Hassfeld, operational information officer, VRR

\section{REFERENCES}

Alphen, W.J.T. van \& H.A. Jongerden, 2013. Variabele Voertuigbezetting en de eerste vijf minuten - Een onderzoek naar de veiligheid en effectiviteit van variabele voertuigbezetting in de eerste vijf minuten na ankomst. Hilversum: Brandweer Gooi en Vechtstreek.

Brandweer, 2018. Normen voor Opkomsttijd. Consulted at https://www.brandweer.nl/brandveiligheid/normen-vooropkomsttijd on 08-06-2018

Brandweer Cluster Amerstreek, 2010. Aflegsysteem lage druk [instructiekaar BRB 300-08]

Brandweer Rotterdam-Rijnmond, 2017. Informatiekaart Complexe gebouwen [CONCEPT]. Rotterdam: Veiligheidsregio Rotterdam-Rijnmond

Brassil, J., 2014. Improving Indoor Positioning Accuracy with Dense, Cooperating Beacons. Procedia Computer Science vol. 40 (pp 1-8). Chicago: Elsevier

Davits, R., P. van Beek \& H. Koomans, 2013. Arbocatalogus Brandweer. Den Haag: Stichting $\mathrm{A}+\mathrm{O}$ fonds Gemeenten. https://extranet.infopuntveiligheid.nl/Infopuntdocumenten/Porta lboekje_AC_Brandweer.pdf

Hagen, R., A. Hendriks, \& J. Molenaar, 2014. Kwadrantenmodel voor gebouwbrandbestrijding.

Lorenz, A.; C. Thierbach; N. Baur; T.H. Kolbe, 2013, Map design aspects, route complexity, or social background? Factors influencing user satisfaction with indoor navigation maps. Cartography and Geographic Information Science, Vol. 40, Number 3, pp. 201-209

Meer, T. van der, 2016. 3D-indoormodellen voor de brandweer - een verkennend onderzoek naar de toepassingsmogelijkheden binnen de veiligheidsketen. TU Delft.

Nagi, R.S., 2004. Cartographic visualization for mobile applications. ITC \& IIRS Master Thesis

Nossum, A.S., 2011. IndoorTubes A Novel Design for Indoor Maps, Cartography and Geographic Information Science, 38:2, 192-200, DOI: 10.1559/15230406382192

Nossum, A.S., \& A.M. Nguyen, 2012. Comparing Two Different Map Types for Patient Navigation Inside a Hospital. In M.-P. K. Ningchuan Xiao (Hrsg.), Proceedings of Seventh International Conference on Geographic Information Science. Columbus, $\mathrm{OH}$.

Roberts, J.C., 2005. Chapter 8 - Exploratory Visualization with Multiple Linked Views. In International Cartographic Association, edited by Jason Dykes, Alan M. MacEachren and Menno-Jan Kraak, Elsevier, Oxford, 2005, Pages 159-180, Exploring Geovisualization, ISBN 9780080445311, https://doi.org/10.1016/B978-008044531-1/50426-7.

Spithorst, S., 2015. Brandweerhandboek 't Brode Boekje handboek voor bevelvoerders bij preparatieve \& repressieve brandweertaken. Susteren: STP Veiligheid en Techniek 
The International Archives of the Photogrammetry, Remote Sensing and Spatial Information Sciences, Volume XLII-4, 2018 ISPRS TC IV Mid-term Symposium “3D Spatial Information Science - The Engine of Change”, 1-5 October 2018, Delft, The Netherlands

Toutziaris, V., 2017. Usability of an adjusted indoorTubes map design for indoor wayfinding on mobile devices. (TU Munchen Master Thesis) retrieved from: http://cartographymaster.eu/wpcontent/theses/2017_Toutziaris_Thesis.pdf

Veiligheidsregio Rotterdam-Rijnmond, 2010. Procedure Inzetplan Complexe Gebouwen 